\title{
Perancangan Rest Area di Kawasan Jalan Tol Trans Sumatera Ruas Pekanbaru-Dumai dengan Penerapan Vernakular Kontemporer
}

\author{
Destia Raudha Fatma dan Bambang Soemardiono \\ Departemen Arsitektur, Fakultas Arsitektur, Desain dan Perencanaan, Institut Teknologi Sepuluh Nopember (ITS) \\ e-mail: bbsoem@arch.its.ac.id
}

\begin{abstract}
Abstrak-Mobilitas merupakan pergerakan manusia dari satu tempat ke tempat lainnya. Dalam melakukan pergerakan ini diperlukannya sebuah fasilitas berupa jalan untuk membantu pergerakan ini sendiri. Dan dari jalan antar daerah ini sendiri pemerintah juga memberikan fasilitas berupa rest area sebagai tempat transisi atau tempat singgah secara temporer. Oleh karena itu diperlukannya suatu identitas pada rest area ini sendiri agar memunculkan identitas yang dapat memberikan kekhasan dan membantu pengunjungnya untuk mengidentifikasi daerah tersebut. Hal ini dapat dilakukan dengan menerapkan vernakular kontemporer pada perancangan untuk memunculkan identitas dari daerah tersebut tanpa harus membuat rancangan itu terlihat sangat tradisional. Untuk mencapai tujuan ini hal yang dapat dilakukan adalah dengan melakukan reinterpretasi tradisi dari daerah sekitar dan menerapkan ke dalam rancangan.
\end{abstract}

Kata Kunci-Mobilitas, Reinterpretasi Tradisi, Rest Area, Vernakular Kontemporer.

\section{PENDAHULUAN}

$\mathrm{M}$ OBILITAS atau perpindahan penduduk yang terjadi di Indonesia merupakan hal yang lumrah pada saat ini. Mobilitas penduduk horizontal atau geografis meliputi semua gerakan (movement) penduduk yang melintasi batas wilayah tertentu dalam periode waktu tertentu pula. Batas wilayah umumnya dipergunakan batas administrasi, misalnya: provinsi, kabupaten, kecamatan, kelurahan atau pedukuhan. Bentukbentuk mobilitas penduduk dibagi menjadi dua, yaitu mobilitas permanen (migrasi), dan mobilitas non-permanen (mobilitas sirkuler) [1]. Perpindahan ini memiliki hubungan yang sangat erat dengan fasilitas-fasilitas yang disediakan untuk mengadakan perpindahan ini sendiri, seperti kendaraan, jalan, dan lain-lain. Kepadatan kendaraan yang terjadi pada saat proses perpindahan ini terjadi juga dapat mengakibatkan kondisi fisik dari pengemudi yang tidak baik dan akhirnya menyebabkan kecelakaan. Di Indonesia sendiri tingkat kecelakaan mengalami peningkatan selama triwulan terakhir. (Gambar 2) Untuk mengurangi angka kecelakaan tersebut pemerintah mengambil kebijakan untuk membangun tempattempat istirahat sesuai dengan jarak yang sudah ditentukan berupa rest area. Tempat-tempat istirahat ini juga bisa disebut sebagai tempat transisi dari satu daerah ke daerah lainnya.

Ini juga mengacu pada konteks perancangan. Karena tempat rest area ini merupakan tempat transisi dari satu daerah ke daerah lainnya, maka pada rest area sendiri dapat diberikan

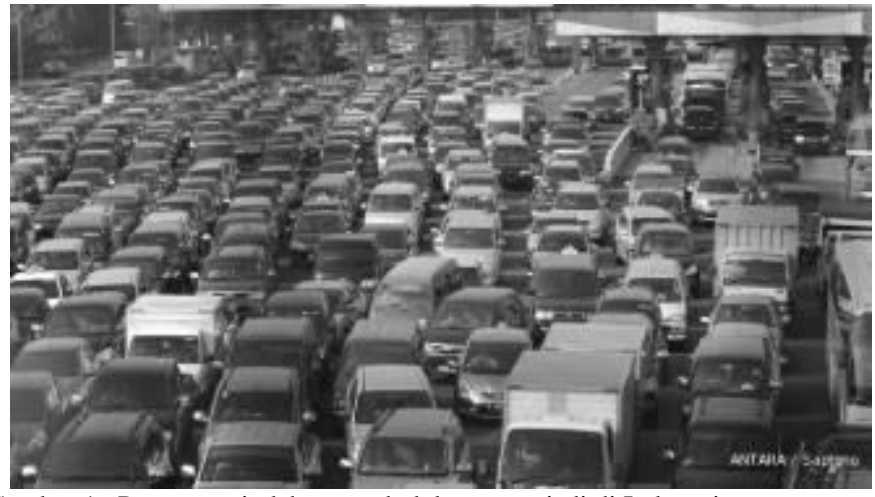

Gambar 1. Potret perpindahan penduduk yang terjadi di Indonesia. (Sumber : google.com)

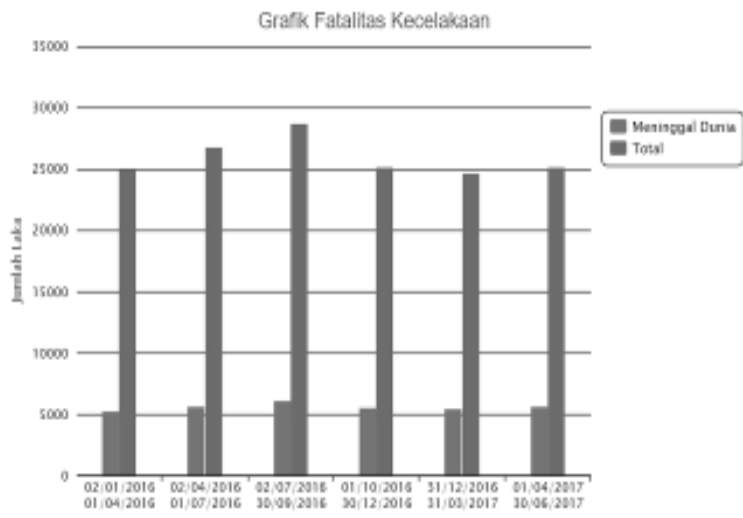

Gambar 2. Kecelakaan di Indonesia selama triwulan terakhir. (Sumber : http://www.korlantas-irsms.info/graph/accidentData)

identitas dari daerah itu sendiri, agar ke khasan dari daerah itu sendiri dapat bangkit.

\section{METODE}

Untuk membangkitkan identitas dari daerah tertentu, maka konteks perancangan merupakan hal yang sangat penting dari rancangan ini sendiri. Perancangan ini sendiri akan dilakukan pada kawasan jalan tol Trans Sumatera ruas PekanbaruDumai. Perkembangan jalur transporasi Pekanbaru-Dumai merupakan salah satu bukti nyata terhadap perkembangan yang terjadi di antara dua daerah tersebut. Hal ini akan berdampak pada meningkatnya volume lalu lintas, yang menciptakan suatu kebutuhan terhadap pengadaan jalan bebas hambatan berupa jalan tol Pekanbaru-Dumai. Selain itu untuk mengakomodasi berbagai aktualita yang terjadi pada ruas jalan tol tersebut, maka perlu dikembangkan suatu fasilitas umum, yaitu berupa 


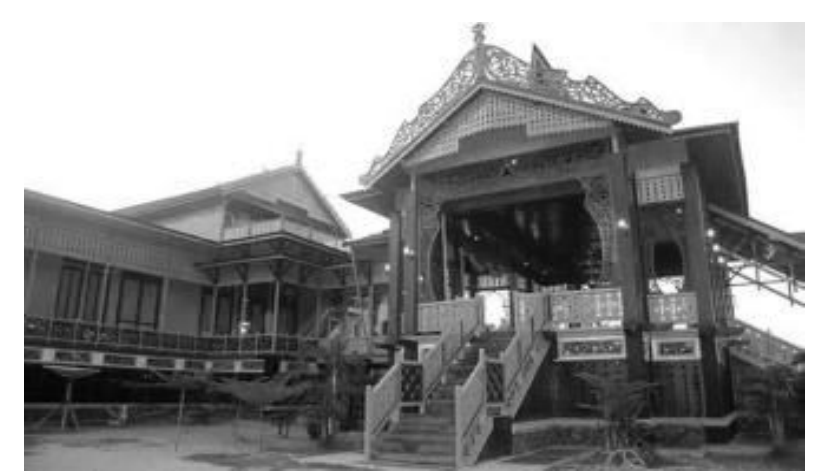

Gambar 3. Arsitektur Vernakular Riau.

Sumber : google.com

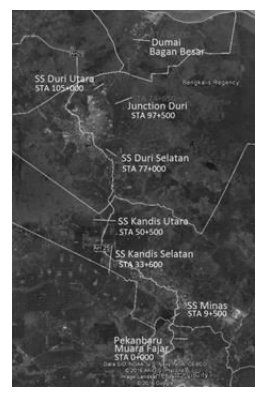

Gambar 4. Rencana Pembangunan Jalan Tol Trans Sumatera Ruas Pekanbaru-Dumai.

Sumber : google.com

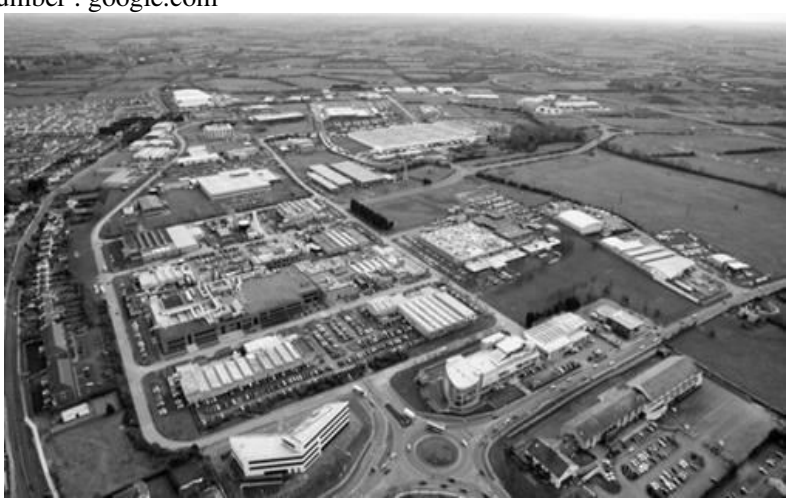

Gambar 5. Dumai sebagai kota industry.

Sumber : google.com

kawasan tempat istirahat (rest area/hub) bagi pengguna jalan tol yang telah melakukan perjalanan jauh.

Obyek rancangan ini menjadi tempat beristirahat di tempat-tempat terjadinya mobilitas penduduk, baik itu sementara maupun dalam skala tertentu. Dalam konteks perancangan di obyek ini, dua tempat yang dihubungkan oleh jalan tol Pekanbaru dan Dumai adalah Pekanbaru, sebagai ibukota dari Riau dan Dumai, sebagai kota industri. Orang yang pergi mengunjungi Dumai adalah orang-orang yang bekerja di industri ini sendiri. Selain itu, Dumai juga terkenal memiliki Bandar Udara Pinang Kampai dan pelabuhan laut, dimana Dumai sendiri berada pada posisi lintas perdagangan internasional Selat Melaka. Pelabuhan ini dibangun sebagai pelabuhan penghubung untuk kegiatan ekspor-impor, dan juga yang ingin menuju ke Malaka, Malaysia [2].

\section{A. Pendekatan Vernakular Kontemporer}

Pendekatan desain berfungsi untuk membantu mengerjakan rancangan agar lebih spesifik, fokus, dan terukur sesuai isu-isu

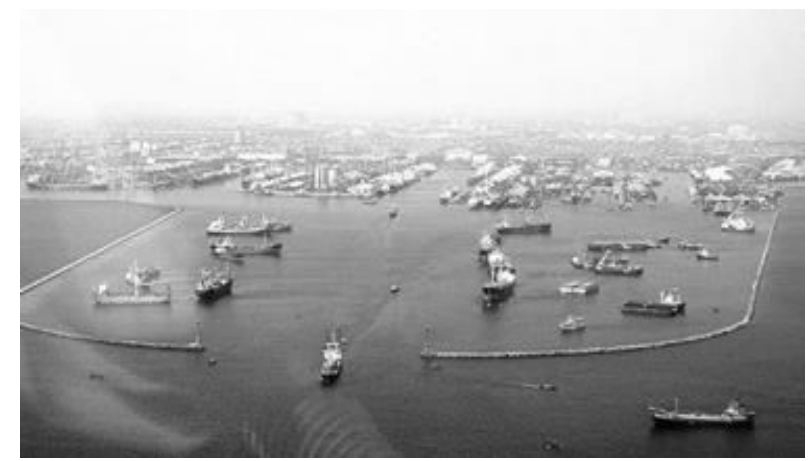

Gambar 6. Pelabuhaninternasional Dumai.

Sumber : google.com

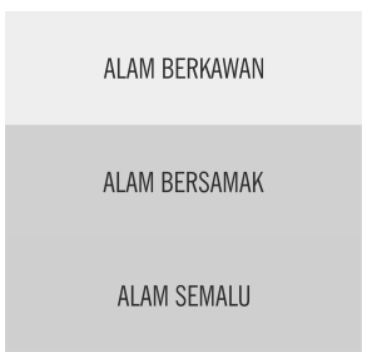

Gambar 7. Pembagian zonasi rumah tradisional Riau, Rumah Lontik. Sumber : Ilustrasi Pribadi

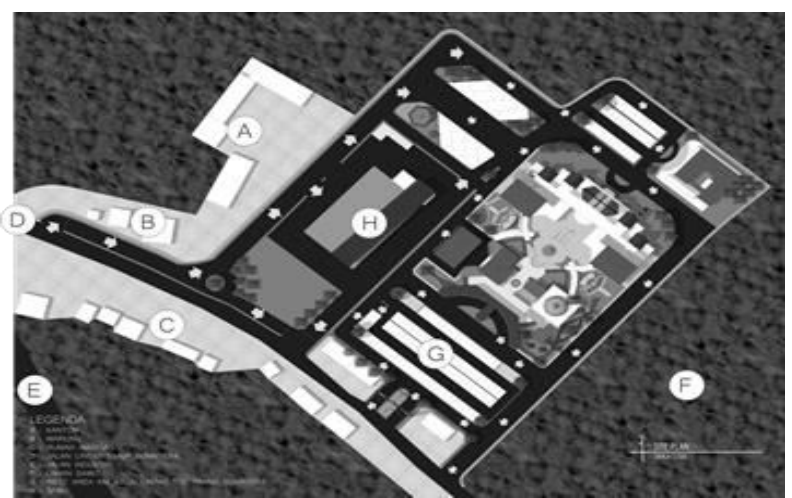

Gambar 8. Pembagian zonasi dari perancangan berdasarkan aktivitas yang terjadi di dalam perancangan.

Sumber : Ilustrasi Pribadi

yang ditangani. Pendekatan desain seperti sebuah arah tujuan yang menjalankan proses dalam merancang.

Dalam obyek ini, menggunakan pendekatan Vernakuler Kontemporer. "Vernacular is the commonly spoken language or dialect of a particular people or place; a local style of architectue, in wich ordinary houses are built". Pendekatan ini dilakukan untuk dapat membantu menghidupkan identitas dari rancangan ini sendiri nantinya

\section{B. Prinsip Reinterpretasi Tradisi}

Reinterpretasi tradisi adalah mengitepretasikan kembali nilai-nilai dan makna yang terkandung dalam tradisi lokal kedalam rancangan arsitektur sehingga menghasilkan suatu rancangan baru yang masih memiliki nilai tradisi/lokalitas setempat

Menurut Tan Hock Beng, reinterpretasi tradisi memiliki arti, yaitu pemaknaan kembali. Yang dimaksud pemaknaan kembali adalah, sebuah hal yang sudah kuno atau tidak zaman sengaja 


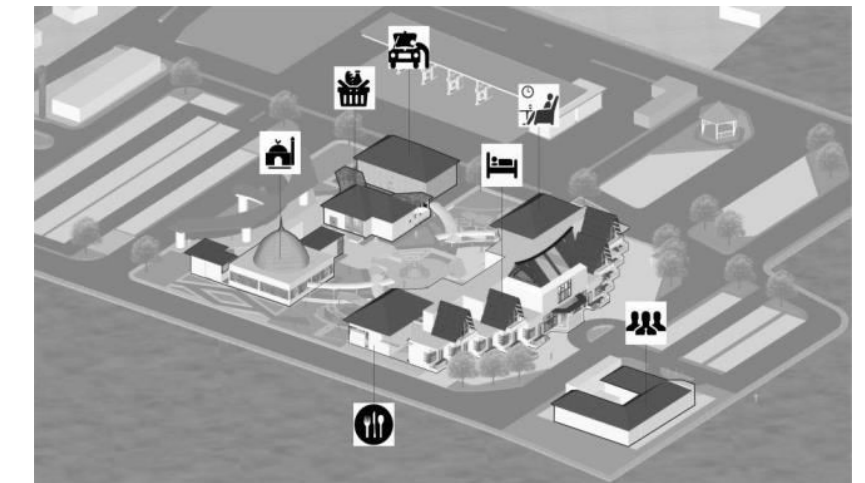

Gambar 9. Reinterpretasi pembagian zona berdasarkan zonasi rumah tradisional Riau, Rumah Lontiok

Sumber : Ilustrasi Pribadi

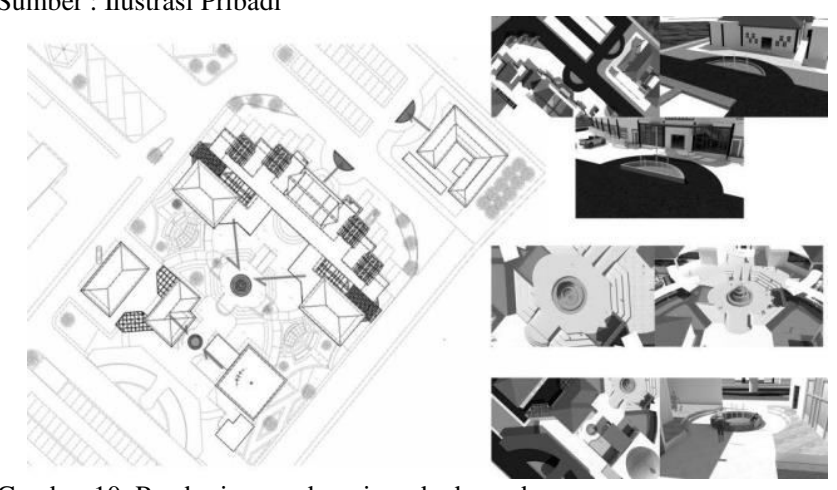

Gambar 10. Pemberian sumber air pada depan bangunan Sumber : Ilustrasi Pribadi

dihadirkan kembali dalam bentuk berbeda namun tetap memiliki nilai-nilai khas yang sama [3].

Terdapat tiga prinsip pada reinterpretasi tradisi, yaitu:

1) Defamiliarisasi

Prinsip defamiliarisasi memiliki arti berarti pengasingan bentuk yang sebenarnya ada namun tidak tampak ada. Prinsip ini memunculkan suatu bentuk dengan wujud nilai yang tidak bisa dilihat namun bisa dirasakan. Prinsip ini diterapkan pada penentuan zoning penataan tapak dan bangunan.

\section{2) Kombinasi}

Prinsip kombinasi pada reinterpretation tradition merupakan suatu upaya penggabungan sesuatu yang lama yang terdapat dalam arsitektur vernakular dengan sesuatu yang baru/modern yang terdapat pada arsitektur kontemporer. Dalam hal ini prinsip kombinasi diterapkan pada pemilihan dan penggunaan material, struktur, dan suasana ruang dalam bangunan.

\section{3) Transformasi}

Prinsip ini merupakan suatu pergerakan/perubahan bentuk yang berkembang dengan memiliki kesenjangan/perbedaan dari bentuk sebelumnya, dengan mengaitkan setiap nilainilai yang ada. Prinsip ini diterapkan pada tampak bangunan obyek rancang dengan melibatkan transformasi bentuk atap pada bangunan.

\section{HASIL RANCANGAN}

Objek rancang merupakan rest area yang akan menerapkan

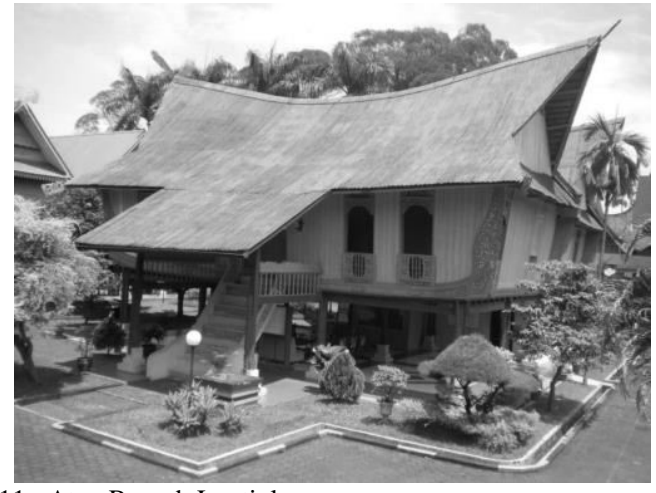

Gambar 11. Atap Rumah Lontiok

Sumber : google.com

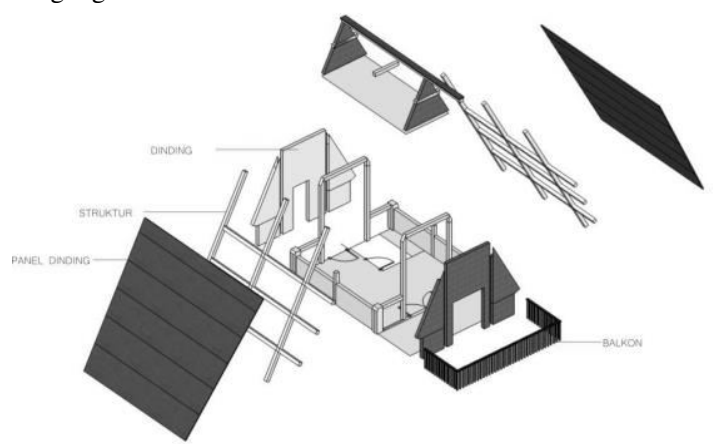

Gambar 12. Kombinasi atap yang sudah di transformasikan dengan material yang lebih modern

Sumber : Ilustrasi Pribadi

pendekatan arsitektur vernakular. Dengan menggunakan metode reinterpretasi tradisi terdapat beberapa cara untuk membangkitkan identitas dari rancangan ini, seperti :

\section{A. Prinsip Defamiliarisasi}

Pembagian zonasi pada site berdasarkan zonasi dari rumah tradisional Lontiok Riau. Rumah Lontiok ini terbagi atas tiga zona, yaitu:

1) Alam Berkawan, yaitu pergaulan antara sesama warga kampung. Pergaulan yang terbatas pada tegur sapa, tanpa adanya hubungan darah ini dilambangkan dengan ruangan muka

2) Alam Bersamak, yakni kaum kerabat dan keluarga. Dilambangkan dengan ruang tengah

3) Alam Semalu, yakni kehidupan pribadi dan rumah tangga. Ini dilambangkan dengan ruang belakang

Dari pembagian zonasi dari rumah tradisional ini dapat dikatakan bahwa semakin ke bagian belakang dari rumah ini, sifat privacy dari rumah tersebut akan semakin besar.

Karena objek memiliki aktivitas yang beragam, dan tentunya aktivitas ini mempunyai tingkat privacy yang beragam, maka site dari objek ini akan dibagi berdasarkan tingkat privacy nya.

Pada Gambar 8 dapat dilihat pembagian zonasi dari Rest Area ini sendiri. Pada bagian depan merupakan zona parkir, dan dilanjutkan dengan Zona A, dimana zona A ini terdiri dari fasilitas berupa mushola, minimarket dan bengkel. Zona ini memiliki tingkat keramaian yang tinggi. Selanjutnya Zona B yang terdiri dari restoran, lounge, dan juga penginapan. Di antara lounge dan restoran ini dihubungkan dengan lobby dan 


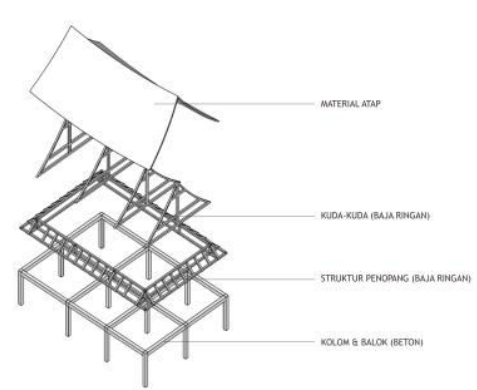

Gambar 13. Struktur atap yang sudah lebih modern

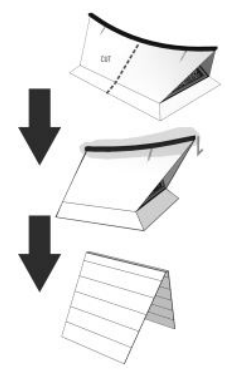

Gambar 14. Transformasi bentuk atap dari atap tradisional Rumah Tradisional Riau, Rumah Lontiok

Sumber : Ilustrasi Pribadi

juga atrium sebagai pemisah dikarenakan tingkat privacy yang berbeda. Dan terakhir, pada bagian belakang merupakan Zona $\mathrm{C}$, dimana pada zona ini merupakan zona pengelola dan juga kelistrikan, yang pastinya tidak semua orang dapat mengakses daerah ini.

Selain dari zonasi, pengadaptasian sumber air dapat dilakukan. Hal ini diadaptasi dari kebiasaan masyarakat asli melayu yang meletakkan bak air di depan rumah mereka.

\section{B. Prinsip Transformasi}

Pada objek desain, bagian atap ini mengalami transformasi menjadi lebih sederhana. Transformasi bentuk, dimana pada perancangan ini mengadaptasi bentuk dari rumah tradisional Riau, yaitu Rumah Lontiok. Atap merupakan bagian dominan yang terdapat pada Rumah Lontiok. Atap mempunyai bentuk melengkung ke atas pada kedua ujung perabungnya. Kaki atap juga melengkung ke atas, tetapi tidak sekuat lengkungan bubungannya.

Pada prinsip kombinasi ini, hasil atap yang sudah di transformasikan, akan dilakukan prinsip kombinasi dengan menggabungkannya dengan material yang lebih modern.

Bagian yang diambil untuk dilakukan proses transformasi adalah bagian ujung dari atap. Hal ini digunakan untuk membuat unit kamar yang nantinya dapat berbentuk segitiga. Ketika sudah diambil bentuk ujung dari atap Rumah Lontiok ini, pada bagian ujung yang menunjuk ke atas diturunkan kebawah, sehingga mempunyai perabung yang lurus, tetapi tetap menjorok ke luar.

\section{Prinsip Kombinasi}

Atap merupakan bagian dominan yang terdapat pada Rumah Lontiok. Atap mempunyai bentuk melengkung ke atas pada kedua ujung perabungnya. Kaki atap juga melengkung ke atas,

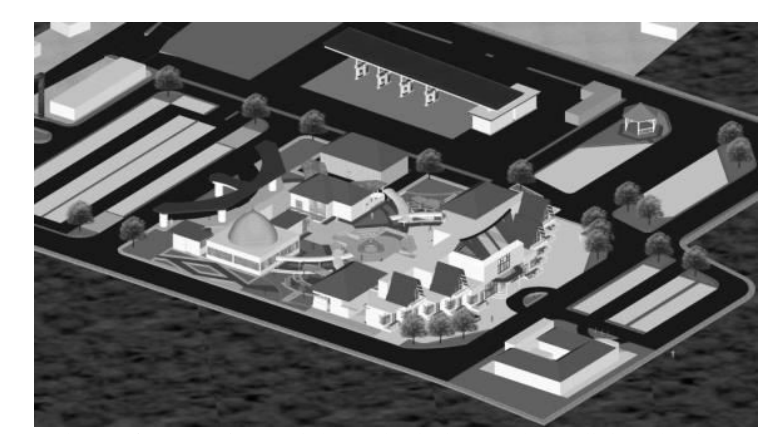

Gambar 15. Transformasi bentuk dari rumah tradisional Riau, Rumah Lontiok

Sumber : Ilustrasi Pribadi

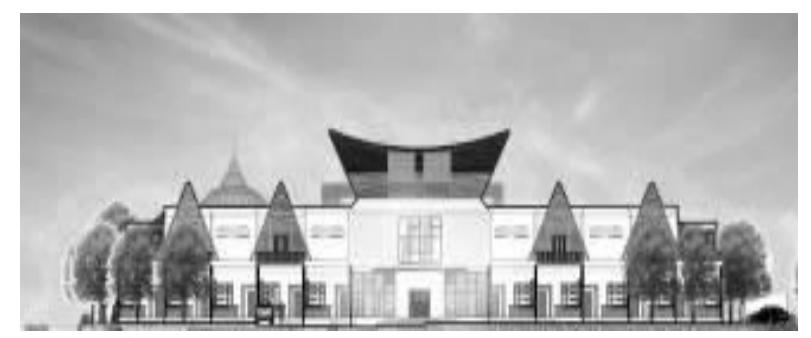

Gambar 16. Penerapan beberapa unsur vernakular kontemporer ke bangunan

Sumber : Ilustrasi Pribadi

tetapi tidak sekuat lengkungan bubungannya.

Pada objek desain, bagian atap ini mengalami transformasi menjadi lebih sederhana, dan juga dikombinasikan dengan material yang lebih modern.

Pada bagian unit kamar yang sudah ditransformasikan dari bentuk atap Rumah Lontiok sebelumnya, akan dikombinasikan dengan material yang lebih modern, seperti rangka struktur yang terdiri dari baja, dinding pada bagian depan-belakang terbuat dari bata, dan juga dinding bagian samping yang berupa panel dinding yang bersifat ringan.

Selain itu pada bagian atap juga menggunakan struktur yang lebih modern, yaitu rangka struktur baja, dan juga penutup yang terdiri dari kaca untuk memasukkan cahaya ke dalam ruangan dan juga galvalum.

\section{KESIMPULAN}

Jalan Tol Pekanbaru-Dumai merupakan bagian dari Jalan Tol Trans Sumatera (JTTS). Ruas ini adalah salah satu ruas yang terletak di provinsi Riau dan akan menghubungkan kota Pekanbaru (Ibukota Provinsi Riau) dengan kota Dumai. Melihat betapa pentingnya Jalan Tol Pekanbaru-Dumai ini, maka seharusnya memiliki fasilitas yang memadai bagi pengguna jalan.

Dengan potensi pengembangan agrobisnis serta status Dumai sebagai kota yang memiliki industri perminyakan yang maju, dan juga infrastruktur pelabuhan dan bandara yang bersifat internasional, maka pengunjung yang diharapkan akan hadir dalam konteks perancangan ini adalah pengunjung yang berasal dari luar maupun warga lokal sendiri. Maka dari itu diperlukannya sebuah identitas yang dapat memberikan kekhasan bagi perancangan akan membantu pengunjung dalam men-identifikasi dari perancangan itu sendiri. 
Usaha yang dapat dilakukan untuk memunculkan identitas itu sendiri dapat melalui penerapan metode Arsitektur Vernakular Kontemporer, dimana pada metode ini objek akan memunculkan image tradisional yang sudah diolah menjadi lebih modern dari daerah itu sendiri.

Hal yang dilakukan oleh penulis diantaranya mentransformasi bentuk tradisional ke dalam objek dan juga memasukkan unsur-unsur tradisional, seperti pemberian unsur air dan pembagian zonasi ke dalam objek itu sendiri.

\section{UCAPAN TERIMA KASIH}

Ucapan terim kasih yang sebesar-besarnya kepada pihak- pihak yang telah membantu di dalam pembuatan Studi ini, dan terima kasih juga atas dukungan dari departemen Arsitektur Institut Teknologi Sepuluh Nopember Surbaya.

\section{DAFTAR PUSTAKA}

[1] I. B. Mantra, "Mobilitas Penduduk di Indonesia dan Implikasi Kebijaksanaan," Yogyakarta, 1984.

[2] Wikipedia, "Kota Dumai." [Online]. Available: https://id.wikipedia.org/wiki/Kota-Dumai. [Accessed: 26-Sep2017].

[3] S. Lim and W.William, Contemporary Vernacular. Singapore: Select Books, 1998. 